\title{
Ensinando Operações Matemáticas com o Uso de Jogos Digitais no Ensino Fundamental
}

\author{
Sivaldo Joaquim ${ }^{1}$, Wilk Oliveira ${ }^{2}$ \\ ${ }^{1}$ Instituto de Computação (IC) \\ Universidade Federal de Alagoas (UFAL) - Maceió, AL - Brasil \\ ${ }^{2}$ Instituto de Ciências Matemáticas e de Computação (ICMC) \\ Universidade de São Paulo (USP) - São Carlos, SP - Brasil \\ sivaldojoaquimeic.ufal.br, wilk.oliveira@usp.br
}

\begin{abstract}
Resumo. A falta de motivação e o baixo desempenho dos estudantes da Educação Básica no domínio de Matemática têm sido um grande problema para comunidade acadêmica. Para ajudar a enfrentar esse problema, nesse artigo relatamos uma experiência de uso de jogos digitais na resolução de operações matemáticas com 83 estudantes do $2^{\circ}$ ano e $3^{\circ}$ ano do Ensino Fundamental I, visando verificar o impacto desses jogos na experiência dos estudantes. Como método de pesquisa, foi utilizada uma abordagem qualitativa com ênfase na observação participante. Dentre os principais resultados, observou-se uma maior interação e trabalho colaborativo entre os estudantes, bem como, uma melhora no seu engajamento e motivação.
\end{abstract}

Palavras-chave: jogos educativos, matemática, educação básica.

Abstract. The lack of motivation and low performance of students of Basic Education in the field of Mathematics has been a major problem for the academic community. To tackle this problem, in this paper we report the experience of using digital games in solving mathematical operations with 83 $2 n d$ and 3rd-grade students of Elementary School 1, to verify the impact of these games on the students' experience. As the research method, a qualitative approach with an emphasis on participant observation was used. Among the main results, there was a greater interaction and collaborative work between students, as well as an improvement in their engagement and motivation.

Keywords: educational games, math, basic education.

\section{Introdução}

No Brasil, nota-se um grande interesse por parte da comunidade acadêmica em utilizar os recursos digitais para inovar nas práticas pedagógicas e impactar positivamente os resultados de aprendizagem dos estudantes da Educação Básica (SANTOS \& SILVA JUNIOR 2016; PALOMINO et al. 2019). No entanto, existem poucos estudos do uso das Tecnologias Digitais de Informação e Comunicação (TDIC) nos anos iniciais do Ensino Fundamental I, principalmente, com estudantes na faixa etária até os 10 anos de 
idade, no domínio de Matemática (REIS et al. 2016; MACÊDO et al. 2017) com foco no desenvolvimento da cultura digital (competência 5) proposta na Base Nacional Comum Curricular (BNCC) (Brasil, 2019). Além disso, diversos outros fatores dificultam o uso efetivo das TDIC no ambiente educacional, tais como, ausência de suporte tecnológico, falta de infraestrutura das escolas brasileiras e ausência de formação continuado dos docentes para seleção e uso adequado dos recursos digitais (FIGUEIREDO et al. 2015; SANTANA e OLIVEIRA, 2019).

Segundo Bacich et al. (2015, p. 47) "estruturalmente, a escola atual não difere daquela do início do século passo". Ao mesmo tempo, de acordo com os mesmos pesquisadores, "os estudantes de hoje não aprendem da mesma forma que os do século anterior" (Bacich et al. 2015, p. 47). De fato, essas constatações não são novidades no Brasil, porém, a busca por estratégias e recursos digitais como ferramentas para auxiliar na mediação didática nos processos de ensino e aprendizagem, continua sendo objeto de estudo por parte de docentes, gestores e pesquisadores de diferentes áreas do conhecimento, níveis e domínios do contexto educacional (BOUCHERVILLE \& VALENTE, 2019; LAURINDO et al. 2019).

Além disso, o baixo desempenho dos estudantes da educação básica na resolução de problemas (Matemática) (ORGANISATION FOR ECONOMIC COOPERATION AND DEVELOPMENT, 2016; BRASIL, 2016) tem motivado a inserção e uso das TDIC para aumentar o desempenho, motivação, engajamento, interação e promover o desenvolvimento de habilidades fundamentais dos estudantes em domínios específicos do conhecimento (SANTANA e SANTOS, 2018; SANTOS e SANTANA, 2018). Neste contexto, o uso de jogos digitais como ferramenta para auxiliar nos processos de ensino e aprendizagem no domínio da Matemática pode contribuir para aumentar a motivação, engajamento e consequentemente, melhorar os resultados pedagógicos no Ensino Fundamental (MACÊDO et al. 2017; PAULA \& VALENTE, 2016).

No intuito de avançar o estado da arte no uso de jogos no Ensino Fundamental I, o presente artigo pretende discorrer sobre a seguinte questão: qual o impacto do uso de jogos digitais no domínio de matemática com estudantes dos anos inicias do Ensino Fundamental I? Para tanto, apresentamos um relato de experiência no uso de três jogos digitais com foco na resolução de operações matemáticas, disponíveis online e gratuitos, denominados: "Ariê Somando",, "Ariê Subtrair" " e "Ariê Tabuada"”, com um total de 83 estudantes, na faixa etária de 7 e 8 anos de idade, do $2^{\circ}$ ano e $3^{\circ}$ ano do Ensino Fundamental I, em uma escola de Educação Infantil, Ensino Fundamental e Médio, situada na região do Baixo do São Francisco, Estado de Alagoas. Neste estudo, foi aplicado como método pesquisa, a abordagem qualitativa com ênfase na observação participante como técnica de coleta de dados.

Os principais resultados identificam que: $i$ ) houve maior interesse dos estudantes ao interagir com os jogos para resolver as operações matemáticas, ii) a utilização dos jogos digitais despertou a atenção dos estudantes, iii) contribuiu positivamente para a

\footnotetext{
${ }^{1}$ Disponível em: http://brincandocomarie.com.br/arie-somando/

${ }^{2}$ Disponível em: http://brincandocomarie.com.br/arie-subtrair/

${ }^{3}$ Disponível em: http://brincandocomarie.com.br/arie-tabuada/
} 
realização do trabalho colaborativo nos processos de ensino e aprendizagem, iv) aumentou a motivação e engajamento na realização das atividades propostas no laboratório de informática, e v) possibilitou um maior diálogo entre os estudantes e professores no ambiente educacional. Diante desses resultados, nota-se que a utilização de recursos digitais, como os jogos, contribuiu positivamente para o desenvolvimento cognitivo, para inclusão dos estudantes na cultural digital e para a construção de novos objetos de aprendizagem no domínio de Matemática. Por meio do nosso estudo, a partir de agora a comunidade acadêmica pode usar os jogos supracitados no ensino de operações matemáticas com estudantes dos anos inicias do Ensino Fundamental I.

\section{Trabalhos Relacionados}

No contexto da Educação Básica, vários pesquisadores da área de Informática na Educação (IE) têm conduzidos estudos visando explorar o potencial dos jogos digitais (OLIVEIRA et al., 2020) para aumentar a motivação, engajamento e contribuir para desempenho de aprendizagem dos estudantes em diferentes níveis e domínios do conhecimento (BRANDÃO et al. 2018). Neste sentido, Macêdo et al. (2017) realizaram um estudo de caso com 26 estudantes na faixa etária de 10 anos de idade, com objetivo de desenvolver e aplicar um jogo educacional com foco no domínio da Matemática como complemento das atividades realizadas em sala de aula com estudantes do $5^{\circ}$ Ano do Ensino Fundamental I. Como resultados, notou-se que houve melhora no desempenho e que a utilização adequada de jogos educativos como ferramenta para auxiliar nos processos de ensino e aprendizagem pode contribuir positivamente no desempenho dos estudantes. No entanto, o referido estudo foi conduzido com um número reduzido de estudantes, dificultando a generalização parcial do estudo e incentivando a realização de novos estudos.

Reis et al. (2016) buscaram investigar o uso dos jogos digitais de Matemática na plataforma Educacross ${ }^{4}$ por meio de cenários colaborativos fundamentados na teoria de aprendizagem Distributed Cognition (Perry, 2003). Para isso, os pesquisadores desenvolveram uma pesquisa com 15 estudantes na faixa etária de 9 e 10 anos de idade, do $5^{\circ}$ ano do Ensino Fundamental I, sendo nove meninas e seis meninos, através do método de investigação de um estudo de caso com abordagem qualitativa. Os principais resultados mostram que os estudantes obtiveram ganhos de aprendizagem. Além disso, observou-se o desenvolvimento de outras habilidades cognitivas como atenção e interpretação. Contudo, o presente estudo também foi conduzido com um número reduzido de estudantes de uma única turma dos anos finais.

Santana e Santos (2018) realizaram um estudo com 34 estudantes com idade entre 10 e 12 anos, do Ensino Fundamental II com o uso de um jogo educacional denominado "Desafio com Palitos" em duas versões: digital e tradicional, com foco no ensino de conceitos específicos de matemática (raciocínio lógico, algarismos romanos e conversão de valores). Como resultados, observou-se que o uso do jogo na versão digital possibilitou um maior engajamento entre os estudantes e a resolução de um número superior de desafios proposto pelo jogo, em comparação aos estudantes que utilizaram a versão tradicional. Além disso, de acordo com os pesquisadores as duas

\footnotetext{
${ }^{4}$ Disponível em: https://www.educacross.com.br/

${ }^{5}$ Disponível em: http://virtualizegames.com/jogo-palitos.html
} 
versões possibilitaram o trabalho em equipe, compartilhamento de ideais e favoreceu o debate no ambiente educacional. Apesar disso, esse trabalho foi realizado com apenas uma turma dos anos inicias do Ensino Fundamental II e com um número reduzido de estudantes.

Em resumo, apesar dos trabalhos evidenciarem resultados positivos do uso de jogos digitais para melhoria no desempenho de aprendizagem. Estes estudos, não abordam a aplicação de jogos digitais com estudantes do $2^{\circ}$ ano e $3^{\circ}$ ano, anos iniciais do Ensino Fundamental I no domínio das operações matemáticas. Além disso, faz-se necessário conduzir novos estudos em ambientes do mundo real e em regiões geograficamente diferentes para avaliar o impacto dos jogos digitais nos processos de ensino e de aprendizagem no contexto da Educação Básica. Assim, até onde sabemos, nosso estudo é o primeiro a trabalhar o uso de jogos digitais com estudantes de diferentes turmas do $2^{\circ}$ e $3^{\circ}$ ano do Ensino Fundamental I, alinhado aos componentes da BNCC.

\section{Estudo}

O estudo foi conduzido com 4 turmas do Ensino Fundamental I, conforme mostrado na Tabela 1, com um total de 83 estudantes, sendo 34 estudantes do sexo masculino e 49 do sexo feminino, com idade entre sete e oito anos. Foram usados os jogos digitais disponíveis online e gratuitos "Ariê Somando", "Ariê Subtrair" e "Ariê Tabuada”. Os jogos utilizados fazem parte de uma plataforma web, denominada "Brincando com Ariê" composta por uma série de jogos educativos para auxiliar no processo de alfabetização de estudantes da Educação Básica (Brincando com Arie, 2019).

Tabela 1. Relação de turmas e número de estudantes participantes.

\begin{tabular}{|c|c|c|c|c|}
\hline \multirow{2}{*}{ Nível } & \multirow{2}{*}{ Ano/Turma } & \multicolumn{2}{|c|}{ Gêneros } & \multirow{2}{*}{$\begin{array}{c}\text { Número de estudantes por } \\
\text { Turma }\end{array}$} \\
\hline & & Masculino & Feminino & \\
\hline \multirow{5}{*}{$\begin{array}{c}\text { Ensino } \\
\text { Fundamental I }\end{array}$} & $2^{\circ}$ Ano "A" & 10 & 14 & 24 \\
\hline & $2^{\circ}$ Ano "B" & 10 & 11 & 21 \\
\hline & $3^{\circ}$ Ano "A" & 9 & 16 & 25 \\
\hline & $3^{\circ}$ Ano "B" & 5 & 8 & 13 \\
\hline & \multicolumn{3}{|c|}{ Total de estudantes } & 83 \\
\hline
\end{tabular}

Segundo Gil (2012, p. 8) para que o "conhecimento possa ser considerado científico, torna-se necessário identificar operações mentais e técnicas que possibilitam a sua verificação". Nesse trabalho, foi utilizada como método de pesquisa uma abordagem qualitativa com ênfase na observação participante como técnica de coleta de dados, tendo em vista a faixa etária dos estudantes e o ambiente natural investigado. Neste contexto Creswell (2010, p. 26) ressalta que a pesquisa qualitativa é "um meio para explorar e entender o significado que os indivíduos ou grupos atribuem a um problema social ou humano". Para Lüdke \& André (2013, p. 31) a "observação permite a coleta de dados em situações em que é impossível outras formas de comunicação".

Para isso, conforme método proposto e usado por Santana e Oliveira (2019) as seguintes etapas foram realizadas: "(1) seleção dos jogos educativos; (2) aplicação dos jogos selecionados em ambiente real; (3) observação da aplicação e coleta dos dados; e (4) análise dos dados coletados", conforme representado no diagrama da Figura 1. 


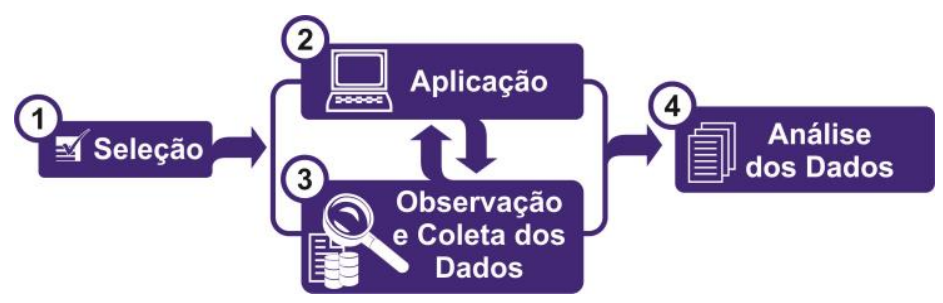

Figura 1. Etapas de execução do estudo (Santana e Oliveira, 2019).

$\mathrm{Na}$ primeira etapa, buscou-se selecionar jogos digitais para auxiliar no ensino das operações matemáticas de estudantes do Ensino Fundamental I, com base na faixa etária de sete e oito anos de idade, design do jogo, interação com usuário, usabilidade e com proposta pedagógica alinhada aos componentes da BNCC, Brasil (2019):

\begin{abstract}
"(EF02MA05) Construir fatos básicos da adição e subtração e utilizá-los no cálculo mental ou escrito". "(EF02MA06) Resolver e elaborar problemas de adição e de subtração, envolvendo números de até três ordens, com os significados de juntar, acrescentar, separar, retirar, utilizando estratégias pessoais ou convencionais". "(EF02MA07) Resolver e elaborar problemas de multiplicação (por 2, 3, 4 e 5) com a ideia de adição de parcelas iguais por meio de estratégias e formas de registro pessoais, utilizando ou não suporte de imagens elou material manipulável". "(EF03MA03) Construir e utilizar fatos básicos da adição e da multiplicação para o cálculo mental ou escrito". "(EF03MA05) Utilizar diferentes procedimentos de cálculo mental $e$ escrito para resolver problemas significativos envolvendo adição $e$ subtração com números naturais". "(EF03MA07) Resolver e elaborar problemas de multiplicação (por 2, 3, 4, 5 e 10) com os significados de adição de parcelas iguais e elementos apresentados em disposição retangular, utilizando diferentes estratégias de cálculo e registros".
\end{abstract}

Como resultado dessa etapa, foram escolhidos os jogos: "Ariê Somando", "Ariê Subtrair" e "Ariê Tabuada". De acordo com a BNCC, "recursos didáticos como malhas quadriculadas, ábacos, jogos, livros, vídeos, calculadoras, planilhas eletrônicas e softwares de geometria dinâmica têm um papel essencial para a compreensão e utilização das noções matemáticas" (BRASIL 2019, p. 276). Na segunda etapa, foram executadas as atividades disponíveis nos jogos digitais, conforme mostrado na Tabela 2.

Tabela 2. Jogos digitais usados no estudo.

\begin{tabular}{c|c|c}
\hline Jogos Digitais & Objetivos & Descrição \\
\cline { 1 - 2 } Ariê Somando & $\begin{array}{c}\text { Resolver operações de } \\
\text { Adição. }\end{array}$ & $\begin{array}{c}\text { Nos jogos “Ariê Somando" e "Ariê Subtrair" o desafio } \\
\text { é praticar as operações de adição e subtração e ajudar o } \\
\text { gatinho "Yuki” a encontrar o tesouro dentro da caverna. }\end{array}$ \\
\cline { 1 - 2 } Ariê Subtrair & $\begin{array}{c}\text { Resolver operações de } \\
\text { Subtração. }\end{array}$ & $\begin{array}{c}\text { Neste jogo, o desafio é praticar a tabuada e levar o } \\
\text { leãozinho "Ariê" até o barco com segurança. }\end{array}$ \\
\hline
\end{tabular}

As atividades foram executadas no período de março a maio de 2019. Os estudantes tiveram uma hora de aula por semana no laboratório de informática com a presença dos professores. No primeiro momento, foi acessada a plataforma "Brincando com Ariê" e foi proposto o jogo digital "Ariê Somando", em seguida, os estudantes foram orientados sobre os níveis do jogo, funcionamento e objetivo do jogo. No segundo momento, os estudantes conheceram o jogo "Ariê Subtrair" e por último, foi utilizado o jogo "Ariê Tabuada". A Tabela 3 apresenta a sequência de aulas. 
Tabela 3. Sequência de aulas com a utilização dos jogos digitais.

\begin{tabular}{|c|c|c|c|}
\hline Aulas & Jogos Digitais & Níveis & Operações Matemáticas \\
\hline 01 & \multirow{2}{*}{ Ariê Somando } & Fácil & \multirow{2}{*}{ Adição de 1 a 10.} \\
\hline 02 & & Dificil & \\
\hline 03 & \multirow{2}{*}{ Ariê Subtrair } & Fácil & \multirow{2}{*}{ Subtração de 1 a 10.} \\
\hline 04 & & Difícil & \\
\hline 05 & \multirow{2}{*}{ Ariê Tabuada } & Fácil & \multirow{2}{*}{ Multiplicação de 1 a 10.} \\
\hline 06 & & Dificil & \\
\hline
\end{tabular}

$\mathrm{Na}$ terceira etapa, foram feitas anotações em um diário de bordo do pesquisador com as observações in loco, fotos, informações descritivas e interação dos estudantes com o uso dos jogos digitais no laboratório de informática com o apoio dos professores para auxiliar no processo de ensino e aprendizagem. Segundo (Lüdke \& André 2013, p. 38) "essas medidas têm um caráter meramente prático, no sentido de ajudar a organização e análise dos dados". Na quarta etapa foi realizada a análise dos dados para identificar o impacto dos jogos na aprendizagem e evidências de engajamento dos estudantes baseado em indicadores extraídos da literatura por Rocha Seixas et al (2016).

\section{Resultados e Discussão}

Incialmente, observou-se o interesse dos estudantes ao interagir com o computador no laboratório de informática para resolver as operações matemáticas. A Tabela 4 mostra de forma sucinta as observações e evidências de engajamento dos estudantes com base nos indicadores extraídos da literatura por Rocha Seixas et al (2016).

Tabela 4. Evidências de engajamento dos estudantes.

\begin{tabular}{|c|c|c|c|}
\hline Atores & Observações & Indicadores & Evidências \\
\hline 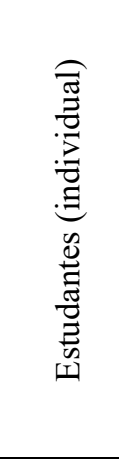 & $\begin{array}{l}\text { Estudante B: “veja, eu } \\
\text { nem preciso contar nos } \\
\text { dedos, olha: } 4+5 \text { é } \\
\text { igual a 9, essa conta é } \\
\text { fácil, tia". }\end{array}$ & $\begin{array}{l}\text { i.Autonomia; } \\
\text { ii.Execução; } \\
\text { iii.Social; } \\
\text { iv.Diversão; }\end{array}$ & $\begin{array}{l}\text { Comportamentos semelhantes foram realizados } \\
\text { por outros estudantes, isso evidência que os } \\
\text { mesmos estão desenvolvendo habilidades } \\
\text { importantes como: (i) autonomia para realizar as } \\
\text { atividades em sala de aula e tomar decisões de } \\
\text { forma independente; (ii) capacidade de executar } \\
\text { as atividades proposta pelo professor; (iii) } \\
\text { estabelecer bom convívio/relacionamento social } \\
\text { com professores e colegas no ambiente } \\
\text { educacional; e (iv) prazer na realização das } \\
\text { atividades com o uso dos jogos digitais. }\end{array}$ \\
\hline 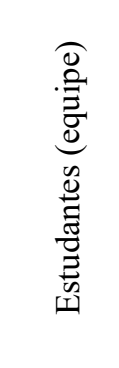 & $\begin{array}{l}\text { Apesar de não } \\
\text { obrigatório, alguns } \\
\text { estudantes formaram } \\
\text { duplas para realizar as } \\
\text { atividades no } \\
\text { laboratório de } \\
\text { informática. }\end{array}$ & $\begin{array}{l}\text { v.Colaboração; } \\
\text { vi.Cooperação; }\end{array}$ & $\begin{array}{l}\text { Em vários momentos, principalmente no início das } \\
\text { aulas, alguns estudantes auxiliaram os colegas de } \\
\text { turma para abrir os jogos educativos disponível na } \\
\text { web e resolver as atividades proposta pelos jogos } \\
\text { educativos, desenvolvendo assim o trabalho } \\
\text { colaborativo (v); além disso, muitos alunos } \\
\text { formaram equipes visando cooperar na realização } \\
\text { das atividades (vi), mesmo não sendo } \\
\text { obrigatórias. }\end{array}$ \\
\hline
\end{tabular}




\begin{tabular}{|c|c|c|c|}
\hline 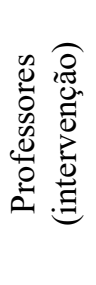 & $\begin{array}{l}\text { Os professores sempre } \\
\text { auxiliaram os } \\
\text { estudantes com mais } \\
\text { dificuldades na } \\
\text { realização das } \\
\text { atividades com o uso } \\
\text { dos jogos digitais. }\end{array}$ & vii.Participação. & $\begin{array}{l}\text { Muitos alunos apresentaram dificuldades para } \\
\text { realizar algumas operações matemática. Nesses } \\
\text { momentos, a (vii) participação do professor foi } \\
\text { fundamental para auxiliar o estudante no processo } \\
\text { de ensino e aprendizagem com o uso dos jogos } \\
\text { educativos. }\end{array}$ \\
\hline
\end{tabular}

Na primeira semana, os estudantes responderam as operações de adição de 1 a 10 (nível fácil) do jogo "Ariê Somando", neste primeiro momento, notou-se a empolgação de alguns estudantes ao realizar as atividades, como por exemplo: o estudante "A" chamou atenção da professora e gesticulando com as duas mãos, mostra dois dedos da mão esquerda e outros três na mão direita e diz: "Ah! Isso é muito fácil! Olha tia: $2+3$ é igual a 5", situações semelhantes foram realizadas por outros estudantes durante a realização das atividades, em um determinado momento, um estudante "B" afirma: "veja, eu nem preciso contar nos dedos, olha: 4+5 é igual a 9, essa conta é fácil, tia”.

No laboratório de informática, vários estudantes formaram duplas para realização das atividades com o uso do jogo digital. Em alguns momentos, observou-se que as duplas auxiliaram umas as outras e também aos colegas individualmente, desenvolvendo assim, um trabalho colaborativo e interação entre os pares na resolução das atividades propostas (OLIVEIRA e JOAQUIM, 2020). Resultados semelhantes foram identificados nos trabalhos de Reis et al. (2016), Santos e Santana (2018) e Santana e Santos (2018). No jogo "Ariê Subtrair" observou uma maior dificuldade na realização das operações de subtração.

No entanto, a professora sempre auxiliou os estudantes durante a realização das atividades com exemplos simples do cotidiano, por exemplo: para o estudante "B", explicou utilizando os dedos "veja, você tem 8 biscoitos e deu 3 para sua coleguinha, quantos biscoitos restaram?", o aluno rapidamente olhou para os dedos levantados na mão da professora e respondeu: "ah! Tia, ficaram 5 biscoitos" e a professora elogiou o estudante: "muito bem, parabéns! Continue fazendo as continhas nos dedos para facilitar". De acordo com Macêdo et al.(2017) "o jogo educativo pode ser uma ótima ferramenta para o auxílio do professor" no ambiente educacional.

Por último, foi proposto aos estudantes o uso do jogo "Ariê Tabuada" visando resolver as operações de multiplicação. Nessa etapa, notou-se alguns estudantes com dificuldades de realizar as operações de multiplicação e em vários momentos pediram ajuda para a professora que sempre auxiliou na resolução das atividades. Além disso, observou-se que os estudantes com habilidades já adquirida nesse tipo de operação matemática auxiliaram outros colegas no laboratório de informática. Em um determinado momento, um estudante clicou sobre uma possível resposta e o resultado estava errado, imediatamente o colega ao lado, falou: "não, não, olha é $12.3 \times 4$ é igual a 12, você pode também somar o número 4 três vezes, assim: 4+4+4 que é 12, entendeu?".

Segundo Boscarioli et al. (2017) "os jogos digitais pedagógicos promovem a desenvoltura do aluno durante seu processo de desenvolvimento intelectual". Em todos os jogos, o "nível fácil" segue uma sequência, por exemplo, no "Ariê Somado": 1+1=, 
$2+1=, 3+1=$ isso para adição de 1 a 10. Assim como no "Ariê Subtrair":1-1=, 2-1=, 3$1=$ para subtração de 1 a 10 e no "Ariê Tabuada": 1x1=, 2x1=, 3x1= para multiplicação de 1 a 10. Muitos estudantes observaram essa sequência de resposta e nesse nível obtiveram $100 \%$ de acertos, um estudante comentou com a professora "olha tia, é muito fácil! É seguir a ordem: $1+1=2,2+1=3,3+1=4,4+1=5$ " o mesmo foi observado nas operações de subtração e multiplicação. No entanto, no "nível difícil" em todos os jogos, as operações são apresentadas com números aleatórios, por exemplo, no "Ariê Somando": 5+1=, 7+1=, 10+1=; "Ariê Subtrair": 6-1=, 3-1=, 10-1; e no "Ariê Tabuada”: 1x1=, 6x1=, 9x1=, para todas as operações matemáticas de 1 a 10.

Diante disso, observou-se que alguns estudantes erraram com maior frequência na resolução das operações. Contudo, com base nas falas e gestos observados pelos professores e anteriormente reportados, observou-se engajamento e motivação dos estudantes na resolução das operações matemáticas, corroborando Macêdo et al. (2017) quando indicam que "a utilização de jogos em sala de aula contribui como fator motivacional". Além disso, ressalta-se, que em vários momentos a professora orientou os estudantes com dicas para resolver os desafios propostos pelos jogos em todos os níveis, para Macêdo et al. (2017) "é necessário que os estudantes sejam orientados na forma de utilizar as tecnologias como ferramenta de auxílio aos estudos".

\subsection{Limitações}

O estudo descrito nesse artigo possui algumas limitações, as quais podem ser solucionadas em estudos futuros. Inicialmente, por usarmos a abordagem de observação participante como meio de coleta, algumas informações podem não ter sido capturadas pelo professor. Para mitigar essa limitação, o professor usou um diário de bordo para fazer todas as anotações que julgava pertinentes. O estudo foi conduzido em uma escola particular, onde uma grande parte dos estudantes já tinham experiência no uso de tecnologias similares. Assim, recomendamos que novos estudos possam ser conduzidos em diferentes escolas (públicas e particulares), a fim de replicar a avaliação em diferentes cenários. Finalmente, nesse estudo, usamos três jogos diferentes, contudo, outros jogos devem ser avaliados a fim de entender se mesmo jogos diferentes afetam da mesma forma a atitude dos estudantes.

\section{Considerações Finais}

O presente estudo relatou o uso de três jogos digitais para auxiliar nos processos de ensino e aprendizagem dos estudantes do Ensino Fundamental I, com foco na resolução de operações matemáticas. Esses recursos, contribuíram para uma maior interação entre a professora e estudantes, melhorando o desempenho dos estudantes, incentivando o trabalho colaborativo, e aumentando a motivação e engajamento dos estudantes na realização das atividades propostas no laboratório de informática com o auxílio da professora. O trabalho contribui com a aplicação e avaliação de jogos educativos digitais no Ensino Fundamental I, abrindo espaço para a inclusão de novos jogos nessa etapa de ensino. Como trabalhos futuros, sugerimos a avaliação de novos jogos digitais e analógicos, visando promover o processo de ensino e aprendizagem no domínio de matemática para estudantes da Educação Básica. 
IX Congresso Brasileiro de Informática na Educação (CBIE 2020)

Anais do XXVI Workshop de Informática na Escola (WIE 2020)

\section{Referências}

BACICH, Lilian; NETO, Adolfo Tanzi; DE MELLO TREVISANI, Fernando. (Orgs.). Ensino híbrido: personalização e tecnologia na educação. Porto Alegre: Penso, 2015.

BOSCARIOLI, Clodis; KAMINSKI, Marcia; JUNKERFUERBOM, Mayara Aline; RIBEIRO, Rhuan Guilherme T. A Experiência de Alunos de uma Escola Indígena nos Primeiros Contatos com Jogos Digitais de Matemática. In: Anais do Workshop de Informática na Escola. 2017. p. 185.

BOUCHERVILLE, Gisele Cristina; VALENTE, José Armando. Mediação Didática e Métodos Inovadores de Ensino e Aprendizagem. REaD-Revista de Educação a Distância, v. 1, n. 1, p. 1-10, 2019.

BRANDÃO, Leônidas; FELIX, Igor; BRANDÃO, Anarosa; PEREIRA, Patrícia. Ensinando com jogos ou jogando com o ensino: a visão da comunidade brasileira de Informática na Educação sobre jogos no ensino de matemática. In: Brazilian Symposium on Computers in Education (Simpósio Brasileiro de Informática na Educação-SBIE). 2018. p. 735.

BRASIL, Ministério da Educação. Base Nacional Comum Curricular. Disponível em: $<$ http://basenacionalcomum.mec.gov.br/abase> Acesso em: 10 out. 2019.

BRASIL. Brasil no PISA 2015: análise e reflexões sobre o desempenho dos estudantes brasileiros. São Paulo: Fundação Santillana, 2016.

BRINCANDO COM ARIÊ. Disponível em: $<\mathrm{http}: / /$ brincandocomarie.com.br $>$ Acesso em: 05 out. 2019.

CRESWELL, John W. Projeto de Pesquisa: métodos qualitativo, quantitativo e misto. $3^{\text {a }}$ ed. - Porto Alegre: Artmed, 2010.

EDUCACROSS. Disponível em: <https://www.educacross.com.br/ >. Acesso em: 22 mai. 2020.

FIGUEIREDO, Gislaine; NOBRE, Isaura; PASSOS, Marize Lyra Silva. Tecnologias computacionais na educação: Desafios na prática docente. In: Anais do Workshop de Informática na Escola. 2015. p. 127.

GIL, Antonio Carlos. Métodos e técnicas de pesquisa social. $6^{a}$ ed. - São Paulo: Atlas, 2012.

LAURINDO, Luis Eduardo Costa; DE MOURA, Ivan Rodrigues; DOS SANTOS, Matias Romário Pinheiro. UmJogo Móvel Baseado em Localização para Motivar e Acompanhar Estudantes no Processo de EnsinoAprendizagem. RENOTE-Revista Novas Tecnologias na Educação, v. 17, n. 3, p. 163-172, 2019.

LÜDKE, Menga; ANDRÉ, Marli E. D. A. Pesquisa em educação: abordagens qualitativas. $2^{\text {a }}$ ed. - Rio de Janeiro: E.P.U, 2013.

MACÊDO, Pedro; MOUTINHO, Mirele; SANTOS, Wylliams. Jogo digital como auxílio no estudo da matemática: Um estudo de caso com estudantes do ensino fundamental i. In: Anais do Workshop de Informática na Escola. 2017. p. 548. 
OLIVEIRA, Wilk; JOAQUIM, Sivaldo. (2020). A Influência dos Jogos Educativos Analógicos e Digitais Interação Social dos Estudantes. In Anais do Workshop de Informática na Escola.

OLIVEIRA, Wilk; JOAQUIM, Sivaldo; ISOTANI, Seiji. (2020). Avaliação de jogos educativos: Desafios, oportunidades e direcionamentos de pesquisa. In Simpósio Brasileiro de Jogos e Entretenimento Digital (SBGames).

ORGANISATION FOR ECONOMIC CO-OPERATION AND DEVELOPMENT. PISA 2015 results (Volume I): Excellence and equity in education. OECD Publishing, 2016.

PALOMINO, P. T., TODA, A. M., OLIVEIRA, W., RODRIGUES, L., \& ISOTANI, S. Teaching Interactive Fiction for Undergraduate Students with the Aid of Information Technologies: An Experience Report. In: RENOTE-Revista Novas Tecnologias na Educação, 2019, 17(3).

PAULA, Bruno Henrique de; VALENTE, José Armando. Jogos digitais e educação: uma possibilidade de mudança da abordagem pedagógica no ensino formal. Revista Ibero-americana de Educação, v. 70, n. 1, p. 9-28, 2016.

PERRY, Mark. Distributed cognition. HCI models, theories, and frameworks: Toward a multidisciplinary science, p. 193-223, 2003.

REIS, R., RODRIGUEZ, C., LYRA, K., ISOTANI, S., STAMATO, É., \& GOTARDO, R. (2016). Experiência de uso de jogos educacionais digitais individuais em contextos de colaboraçao. In Anais do Workshop de Informática na Escola (Vol. 22, No. 1, p. 485).

ROCHA SEIXAS, Luma; GOMES, Alex Sandro; DE MELO FILHO, Ivanildo José. Effectiveness of gamification in the engagement of students. Computers in Human Behavior, v. 58, p. 48-63, 2016.

SANTANA, Sivaldo Joaquim de; OLIVEIRA, Wilk. Jogos Educacionais como Ferramenta de Auxílio ao Processo de Alfabetização. In: Anais do Workshop de Informática na Escola. 2019. p. 148.

SANTANA, Sivaldo; SANTOS, Wilk Oliveira. Jogos Educativos no Ensino de Matemática: Qual a Melhor Abordagem? In: Anais do Workshop de Informática na Escola. 2018. p. 80.

SANTOS, W. O., \& SILVA JUNIOR, C. G. Virtualização de jogos educativos: Uma experiência no ensino de matemática. In: Revista Brasileira de Informática na Educação, 2016,24(02), 108.

SANTOS, Wilk Oliveira; SANTANA, Sivaldo Joaquim. Os Jogos Digitais São Realmente Melhores que os Jogos Tradicionais para Ensinar Matemática? Uma Análise sob a Concentração dos Estudantes. RENOTE-Revista Novas Tecnologias na Educação, v. 16, n. 1, 2018. 